УДК 008

DOI: $10.17223 / 22220836 / 23 / 2$

\title{
О.А. Бойко
}

\section{АРХЕТИП «ТЕНИ» В ИСКУССТВЕ ХХ В.}

\begin{abstract}
В статье предложено использовать архетипический подход Карла Густава Юнга для анализа произведений искусства XX в. В иелях исследования выбирается один из архетипов коллективного бессознательного - архетип «тени», проявления которого в искусстве ХХ в. автор показывает на примерах картин Эдварда Мунка, Казимира Малевича и Макса Эрнста. В прочессе исследования проявлений архетипа «тени» в произведениях искусства XX в. осуществляется анализ общих тенденций культуры данного времени.

Ключевые слова: К.Г. Юнг, коллективное бессознательное, архетип «тени», Эдвард Мунк, Казимир Малевич, Макс Эрнст.
\end{abstract}

В культуре XX и начала XXI в. огромную роль играют бессознательные механизмы, которые ярко проявляются во многих сферах жизни общества. Высшим воплощением их действия стали те бедствия, с которыми столкнулся мир прошлого столетия, когда, казалось бы, в недрах цивилизованного общества с невиданным ранее масштабом распространились идеи нацизма, экстремизма и геноцида. С сожалением приходится признать, что ужасные отголоски этих явлений пробудились в душах современных народов. Проявляясь во всех сторонах человеческой жизни, бессознательные процессы особенно чётко просматриваются в искусстве, которое начиная с XX в. резко сменило вектор своего развития в сторону новых авангардистских форм. На наш взгляд, довольно продуктивным методом их понимания станет исследование с применением архетипического подхода, разработанного автором теории коллективного бессознательного, великим швейцарским мыслителем Карлом Густавом Юнгом.

Архетипы, по К.Г. Юнгу, представляют собой структурные элементы всечеловеческой психики - коллективного бессознательного. Роль архетипов в культуре сравнима с ролью инстинктов в жизни животных. Архетипы - исключительно человеческие психические формы, рождающиеся в конкретном человеке вместе с генетической информацией. При этом Юнг подчёркивает, что это именно структуры и формы психики, а не приобретаемое уже в течение жизненного опыта смысловое содержание. Архетип в символической форме привносит в психику конкретного человека образцы и мотивы психики всего человечества. Проявляясь в человеческой жизни в форме символов, архетипы несут скрытый для рационального понимания глубокий общечеловеческий смысл. Архетипы постоянны, они не исчезают, их невозможно подавить или вытеснить. Попытки такого подавления опасны психическими заболеваниями для того, кто их предпринимает: от конкретной личности до человечества в целом. В качестве ярких примеров архетипов можно назвать архетипы бога, героя, мудреца, вождя, добра и зла, волшебника, доброго по- 
мощника, ребёнка, матери, демона, злодея, женского и мужского начала. Одним из наиболее интересных архетипов, по Юнгу, является архетип «тени».

Архетип «тени» воплощает неосознаваемые качества человеческой психики, проецируемые вовне. Как правило, это этически и эстетически неприемлемые («тёмные») стороны индивидуальной и коллективной души. Как и все архетипы, «тень» существует на коллективном уровне, неминуемо проявляясь в психике конкретных людей. На индивидуальном уровне «тень» включает негативные стороны личности, её бесконтрольные инстинкты. Она - та сторона личности, которую человек скрывает сам от себя, предпочитая не замечать её. Юнг называет «тень» «моральной проблемой, бросающей вызов личностному эго в целом» [1. С. 20]. Согласно мыслителю ни один человек не в состоянии осознать свою «тень», не приложив серьезных усилий морального характера, так как её осознание предполагает признание реального присутствия темных аспектов личности. Юнгианский автор Мария-Луиза фон Франц пишет: «При попытке увидеть свою Тень человек начинает замечать у себя (к своему стыду) те качества и импульсы, наличие которых он обычно отрицает, хотя и различает у других: эгоизм, леность ума и небрежность мысли, прожектерство, безответственность и трусость, чрезмерную страсть к деньгам и вещам - одним словом, все те грешки, о которых раньше он думал: “Ерунда, никто этого не заметит и вообще, кто не без греха"» [2. C. 165]. По мысли Юнга, при наличии интенции воли «тень» может быть до некоторой степени ассимилирована сознательной частью личности, но в ней присутствуют те или иные черты, демонстрирующие крайне упорное противодействие моральному контролю, и повлиять на них оказывается почти невозможно (см.: [1. С. 21]).

Человек, не замечающий своей «тени», будто надевает на себя некую завесу, не позволяющую ему видеть себя и мир реальными. Такой человек проецирует на мир собственную «тень», искажающую его мировоззрение. Так как человек не осознаёт наличие у себя «тени», он подавляет те её свойства, которые при определённых обстоятельствах могли бы играть конструктивную роль. В результате подавления эти свойства становятся негативными.

Сознание-«эго» находится с «тенью» в постоянном конфликте, который Юнг называет «битвой за освобождение» (см.: [2. С. 117]). Юнгианский автор Джозеф Л. Хендерсон считает, что в борьбе первобытного человека за обретение сознания этот конфликт выражался в противоборстве архетипического героя с космическими силами зла в обличии драконов и других чудовищ. В развивающемся сознании индивида образ героя олицетворяет средство, с помощью которого нарождающееся «эго» преодолевает инерцию бессознательного разума и освобождает зрелого человека от регрессивного стремления вернуться к блаженному состоянию младенца (см.: [2. С. 117-118]).

Однако помимо негативных человеческих качеств К.Г. Юнг наделяет «тень» и некоторым позитивным моментом: к её сфере относится та часть человеческой личности, которая находится на стадии становления. Таким образом, автор относит к области «тени» огромный потенциал, заложенный в человеке. Следует отметить также, что «тень» представляет собой не просто противоположную сторону сознательного «эго», она тесно связана с ним. Подобно тому, как «эго» содержит неприятные и деструктивные установки, 
так и «тень» имеет морально положительные качества - нормальные инстинкты и созидательные импульсы. М.-Л. фон Франц пишет: «Станет ли Тень нашим другом или врагом, зависит главным образом от нас самих. ... Тень вовсе не обязательно находится в оппозиции. На деле она в точности подобна любому человеку, ради сосуществования с которым приходится то в чем-то уступить, то в чем-то пойти наперекор, а то и что-то полюбить в зависимости от ситуации. Тень становится враждебной, только когда ее игнорируют или недопонимают...» [2. С. 170-171].

На коллективном уровне архетип «тени» наиболее явно проявляется в религиозных образах. Особенно это касается мировых религий, в которых чётко противопоставляется желаемое и должное. В результате человек начинает активно подавлять свои «теневые» качества и побуждения как греховные. При этом вытесняемые «цивилизованным обществом» аспекты архетипа «тени» находят свою достойную персонификацию в образах «нечистой силы». Воспитанный таким образом человек считает, что всё «настоящее», что в нём есть, - это светлые высокоморальные качества, происходящие от Бога, а всё зло и «низменные инстинкты» так или иначе связаны с искушением дьявола и достойны только искоренения. Так, энергия агрессии и либидо, которые, будь они приняты в себе человеком, могут играть конструктивную роль в его жизни, порой жестоко подавляются по религиозным и этическим причинам, вызывая лишь невротизацию и чувство вины.

Ещё одна важнейшая сфера, в которой явно прослеживается коллективный аспект «тени», это искусство. Будучи тесно связанным с религиозной и этической сферами, искусство воплощает в себе и нравственные интенции подавления «тени» и бессознательные аспекты потребности высвобождения энергии этого архетипа. На наш взгляд, наиболее полно архетип «тени» стал воплощаться и объективироваться в искусстве XX в. Именно архетип «тени» позволяет охарактеризовать то, что Х. Ортега-и-Гассет в своё время назвал дегуманизацией современного ему искусства. Будучи непосредственным отражением архетипических символов своей эпохи, искусство способно через отдельных творцов показать особенности душевного состояния целого народа, эпохи и культуры. Искусство ХХ в. действительно утратило человеческое лицо, обнаружив вырвавшиеся из глубин коллективной психики долгое время подавляемые за гармоничной маской «демонические» пугающие, непонятные и завораживающие образы.

Прежде чем приступить к архетипическому анализу некоторых шедевров $\mathrm{XX}$ в., целесообразно также вспомнить юнговскую типологию произведений искусства. Эта типология в определённой степени позволяет понять, какое творение представляется возможным рассматривать как продукт коллективного бессознательного, а какое не требует такой интерпретации. Речь идёт о таких типах художественных произведений, как «психологический» и «визионерский». Первый тип предлагает аудитории тот материал, который является доступным для непосредственного осознания. Его произведения интерпретируются с точки зрения жизненного опыта автора и его окружения, его знаний, переживаний, представлений о некоторых событиях. Образы таких произведений связаны с обыденной жизнью людей и с тем, что называют повседневностью. Соответственно, для анализа таких произведений не требует- 
ся использование архетипического подхода. Напротив, «визионерский тип» творчества не имеет ничего общего с привычным и понятным сознанию. Это некий материал, который, как пишет Юнг, «наделён чуждой нам сущностью, потаённым естеством, и происходит он как бы из бездн дочеловеческих веков или миров сверхчеловеческого естества, то ли светлых, то ли тёмных, - некое первопереживание, перед лицом которого человеческой природе грозит полнейшее бессилие и беспомощность» [3. С. 128-129]. Значимость этого переживания согласно Юнгу связана с мощным эмоциональным потрясением, которое испытывает творец. В таком случае нельзя сказать, что именно автор создаёт произведение. Скорее он является его транслятором, передавая аудитории некое содержание коллективного бессознательного.

Теперь будет логичным остановиться на некоторых конкретных проявлениях «тени» в мировом искусстве XX в., сосредоточившись на живописи, в которой, на наш взгляд, прослеживаются наиболее наглядные образы данного архетипа. Поскольку объём данной работы ограничен, остановимся на тех шедеврах мирового искусства, которые кажутся нам наиболее показательными в контексте данного размышления.

Одним из первых из этого перечня произведений, на наш взгляд, является картина норвежского художника-экспрессиониста Эдварда Мунка «Крик» (1893 г.), ставшая затем темой для серии работ художника конца XIX - начала $\mathrm{XX}$ в. Несмотря на то, что работа по многим описаниям создана в результате желания передать ужас, охвативший автора во время одной из прогулок при виде небывало яркого заката, т.е. эмоцию конкретного человека, полагаем, сила этой эмоции гораздо глубже. Это то самое проявление энергии коллективного бессознательного в художественных произведениях «визионерского типа», о котором писал К.Г. Юнг. Эмоция, которая не отпускала автора на протяжении почти двадцати лет, когда он писал серию работ, по-разному обыгрывающих «Крик», является бессознательным предчувствием ужаса перед назревающим прорывом архетипа «тени» в реальность ХХ в.

Детали картины позволяют чётко воспринять это. Так, на первом плане картины предстаёт существо, настолько охваченное ужасом, что в нём трудно видеть конкретные человеческие черты. Оно доведено до схематизации. Его положение выражает шаткость опоры под ногами, а охваченное ужасом лицо отсылает ко многим образам сразу. Неконкретность, собирательность образа подчёркивает его бессознательный характер. Так, давая характеристику этой фигуре, исследователи используют такие слова, как призрак, эмбрион, скелет и даже сперматозоид. Такие характеристики, воплощающие одновременно смерть и рождение новой жизни, сами по себе являются выражением архетипа смерти и возрождения испокон веков, духовно питающего западную культуру.

Вся природа на картине будто кричит, вторя человеческому страданию, которое, судя по яркости фона, приобретает небывалый размах. Мост над пропастью будто символизирует опасный переход в будущее (эпоху XX в.), которое, как видно по реакции персонажа картины, носит катастрофический характер. Двое чинно гуляющих на дальнем плане людей, словно не замечающих трагедии, с помощью контраста усиливают угнетающий эффект. Возможно, они воплощают образы безразличия и нежелания понимать ужас происходящего и разделять боль страдающих. Это на определённом этапе 
будет естественным состоянием многих людей, которые под влиянием коллективного безумия будут выполнять приказы об уничтожении невинных. Это одно из произведений искусства, которое было, на наш взгляд, сигналом, предупреждением со стороны бессознательного людям XX в.

Удивительно ёмким воплощением архетипа «тени» в отечественном искусстве начала XX в. стала самая известная работа Казимира Малевича «Чёрный квадрат». Картина была впервые выставлена на футуристической выставке «0,10» в декабре 1915 г. и имела большой общественный резонанс. Работа, выполненная Малевичем летом и осенью 1915 г. за два года до Октябрьской революции 1917 г., представляет собой явный пример предчувствия художником радикальной ломки истории и тёмного времени. На указанной выставке супрематические произведения Малевича занимали отдельный зал. Крайне символично, что «Черный квадрат» висел среди тридцати девяти супрематических картин, на самом видном месте, в так называемом «красном углу», где обычно вешают иконы. Существует мнение, что тем самым Малевич пророчески уловил суть зарождавшего современного искусства и явил миру его новый идеальный образ.

Не менее символичной предстаёт и предыстория появления картины. В 1913 г. К.С. Малевич работал над декорациями и костюмами к постановке оперы «Победа над солнцем». Именно в эскизах этих декораций впервые возникло изображение черного квадрата как выражение победы творчества человека над пассивностью природы. Символически это выглядело так: черный квадрат вместо солнечного круга. С точки зрения юнгианского анализа, в котором свет - это символ сознания, данная метафора К.С. Малевича может трактоваться как победа бессознательного над сознанием, подавление сознания. Также солнце с точки зрения архетипической символики олицетворяет нечто высшее, божественное. Соответственно «победа над солнцем» может интерпретироваться как отказ от религиозности, что и произойдёт в скором времени под влиянием официальной идеологии Советского Союза.

Отечественный искусствовед и историк искусства А.С. Шатских во вводном слове к собранию сочинений основателя супрематизма отмечала, что возникновение «Чёрного квадрата» сопровождалось у К. Малевича мощным экстатическим ощущением. По её словам, данная картина - это «чувственная трансценденция живописного опыта» [4. С. 12]. С точки зрения юнгианского анализа подобные эпитеты чувства, испытанного художником, заслуживают особого внимания, поскольку это свидетельство так называемого нуминозного опыта - трудно вербализируемого переживания от соприкосновения с энергией сакрального в поле коллективного бессознательного.

Важно отметить, что после создания этого произведения Малевич, испытал именно то состояние, которое, по Юнгу, характерно для создателей произведений «визионерского типа». После воплощения в жизнь «Чёрного квадрата» Казимир Малевич долгое время не мог ни спать, ни есть, пытаясь понять своё произведение. Вряд ли подобная реакция была бы у автора, если бы он просто воплотил новую интеллектуально-художественную форму, которую в данном творении часто видят исследователи. О том, что анализируемое произведение есть продукт бессознательного, свидетельствует и тот факт, что 
на упомянутой выставке рядом с картинами Малевича висело уведомление автора о том, что содержание многих из них ему неизвестно (см.: [5. С. 23]).

По нашему убеждению, «Чёрный квадрат» - это не только продуманный революционный вызов конкретного художника, это в равной степени самоотражение эпохи. В этой связи можно провести аналогию с идеей Гегеля о том, что искусство является одной из форм самосозерцания Абсолютного духа. Видимо, размышляя в том же ключе, Малевич писал: «Мы - печать своего времени» [4. С. 57]. Чернота квадрата, на наш взгляд, является символом века, в котором долгое время подавляемый за маской цивилизованности и рациональности, архетип «тени» проявляется в небывалой агрессивности и безрассудности революции, мировых войн и идей национализма, охвативших мир.

Нужно отметить, что сам родоначальник супрематизма высоко ценил роль бессознательного и осознавал его конструктивное значение для искусства. В одной из своих заметок он написал: «Нам мешает быть в мире наше сознание. <...> Подсознание уже на пороге к Миру, и только когда подсознание теряет окончательную связь с сознанием... тогда наступает Мир в человеке» [5. С. 398].

Ещё одним ярким примером проявления архетипа «тени» в мировом искусстве стал стиль сюрреализма, сознательно направленный на высвобождение образов подсознательного. Возникший под влиянием идей психоанализа 3. Фрейда, сюрреализм выводит на всеобщее обозрение те образы и мотивы, которые до XX в. сдерживались моральными и религиозными табу. Сюрреализм показывает, что искусство не просто инструмент для воспроизведения красоты мира. Оно способно выходить за границы физически реального, и в этом его подлинная свобода. Разбивая клетку ханжеской морали, так называемого цивилизованного человечества, искусство может показывать психическую реальность во всей её неприглядности. Произведения сюрреализма направлены на раскрытие беспредельного творческого потенциала не только у художника, но и у зрителя, восприятие которого, основанное на собственных психологических проекциях, становится бессознательным соавторством.

На наш взгляд, многие образы, созданные сюрреалистами, являются архетипическими. Особенно это касается воспроизведения мастерами этого направления шокирующих своей интерпретацией религиозных сюжетов. Архетипический характер символов в работах этого жанра закреплялся в коллективной психике людей многих поколений. Теперь же эти образы предстают в пугающем негативном свете, подвергаясь радикальному осквернению. В качестве примера можно привести картину Макса Эрнста «Мадонна, шлепающая младенца Христа перед тремя свидетелями». На этой картине, впервые выставленной в 1926 г. на выставке независимых художников в Кёльне, показана сцена, изображающая Мадонну, в агрессивном порыве замахивающуюся рукой на лежащего у неё на коленях младенца-Христа, с которого в ходе этого действа слетает нимб. В окно за этой сценой с безразличным видом подсматривают три человека, которые, очевидно, воплощают всю жестокость человеческого безразличия.

Возникает вопрос, почему мастер создаёт такие произведения? Только ли для того, чтобы эпатировать общественность? На наш взгляд, это не единственная причина. Подобные образы, отталкиваемые обществом, но всё же 
привлекательные для него, являются высвобождением древних этически нейтральных и поэтому более целостных архетипических символов, чем принятые в современном цивилизованном обществе. С точки зрения К.Г. Юнга, архетипы христианства в XX в. утратили способность давать духовную подпитку западному человеку. Швейцарский автор пишет о том, что древние языческие образы богов, в которых нет одностороннего разделения на абсолютно светлые (положительные) и темные (отрицательные) этические качества более полно отражают природу многогранной психики человека, в которой уживаются «светлые» и «тёмные» стороны. Юнг обращает внимание на тот факт, что религии, которые выдвигают на первый план абсолютно идеального с этической точки зрения бога, являются достаточно поздними и молодыми образованиями по сравнению с языческими культами, боги которых воплощают этически нейтральные древние архетипы человеческой психики. Христианские догмы заставляют человека подавлять теневые стороны своего естества. Однако такое подавление часто не приводит к добру, только увеличивая невротизацию западного цивилизованного общества. Древние же языческие культы, герои и боги которых не стеснялись своих негативных качеств, позволяли человеку быть ближе к корням своей психики, ближе к самой природе. Разочарованность в христианстве заставляет западного человека активно искать новые духовные пути, зачастую возвращаясь к древнейшим, менее морализированным формам религиозности. По этому поводу К. Юнг пишет: «Современный человек идёт к внутреннему, к созерцанию тёмных оснований души. Это происходит с тем же скептицизмом и такой же безжалостностью, с какими Будда был принуждён смести два миллиона богов, чтобы достичь единственно достоверного изначального опыта» [6. С. 220].

Обращаясь к описанной выше картине Макса Эрнста с точки зрения архетипического подхода Юнга, мы можем полагать, что на ней воплотился древний архетип Великой Матери. Данный архетип испокон века возрождавшийся в образах великих богинь, представлял их качества как этически амбивалентные. Древние богини воспринимались как те, кто одновременно дает и забирает жизнь, награждает и жестоко карает людей. Именно такими были египетская Исида, греческая Гера, индийская Кали, американская ИшЧель и многие другие. Образ Богородицы, с точки зрения юнгианства, является одним из поздних проявлений архетипа богини. Как справедливо замечает юнгианец Бернар А. Лиэтар, будучи просто женщиной, на которую снизошёл Бог, Пресвятая Дева почитается в западном мире наравне с самим Богом. Не случайно многие храмы западного мира посвящены именно Богородице, а сама христианская церковь воспринимается как Мать (см.: [7. С. 57-71]). Таким образом, Пресвятая Дева - это проявление архетипа Великой Матери, в котором выражены только «светлые» стороны и подавлены «тёмные». На анализируемой же картине Макса Эрнста мы видим именно теневую, долгое время подавляемую культурой сторону архетипа Великой Матери, которая, видимо, возникает в искусстве XX в., поскольку была нужна человечеству для психологической компенсации.

Подобного плана шокирующие своей дерзкой интерпретацией и одновременно привлекающие христианские образы не являются редкими исключениями в искусстве XX в. Мы можем их видеть у других сюрреалистов. По 
нашему мнению, самые яркие из них встречаются в картинах Сальвадора Дали, Поля Дельво и Зигфрида Задемака. Думается, что сам факт повторяемости, типичности подобных сюжетов свидетельствует об определённой тенденции эпохи к освобождению древних архетипов. Конечно, можно было бы объяснить появление подобных мотивов модой, дурным вкусом, изъянами автора, отсутствием цензуры и рядом подобных причин. Однако с точки зрения юнгианской теории, которой мы придерживаемся, такие феномены всегда глубже, поскольку они символически отражают состояние коллективной психики.

Итак, с точки зрения архетипического подхода К.Г. Юнга человеческая коллективная психика, будучи сложным саморегулирующимся образованием, выполняет через искусство несколько важных функций: во-первых, она непроизвольно отражает своё собственное состояние через художественный образ в произведениях «визионерского» типа; во-вторых, она доводит своё состояние до общественного восприятия; в-третьих, стремится исцелить, компенсировать наиболее опасные свои состояния.

Архетип «тени» - самое сложное проявление общечеловеческого бессознательного, поскольку его образы априори стремятся к максимальному вытеснению. «Дегуманизированное» искусство XX в., как мы старались показать в данной статье, обнажает архетип «тени», доводя его до уровня коллективного самосозерцания человечества конкретной эпохи. Художественные образы, воплощённые в картинах Э. Мунка, К.С. Малевича, М. Эрнста и многих других представителей авангардистского и модернистского искусства XX в., - это не просто новая форма творчества, это ещё и послания коллективного бессознательного, которые авторы транслировали современникам, делая явным то, что уже готовилось к реальному воплощению в обществе и сознании людей. Исходя из этого, мы понимаем, что с точки зрения юнгианского подхода новаторские направления искусства ХХ в. стали не только вызовом обществу, но и его насущной потребностью, удовлетворение которой осуществляется и сейчас в искусстве постмодернизма.

\section{Лuтература}

1. Юнг К.Г. Эон. М. : АСТ, 2009. $411 \mathrm{c}$.

2. Юнг К. Г., фон Франц М.-Л., Хендерсон Дж. Л., Якоби И., Яффе А. Человек и его символы. М. : Серебряные нити, 1997. 368 с.

3. Юнг К.Г. Собрание сочинений: в 19 т. М. : Ренессанс, 1992. Т. 15: Феномен духа в искусстве и науке. $320 \mathrm{c}$.

4. Малевич К. Собрание сочинений: в 5 т. М. : Гилея, 2004. Т. 5.624 с.

5. Майкапар А. Малевич. М. : Комс. правда, 2011.48 с.

6. Юнг К.Г. Проблема души современного человека // Юнг К.Г. Архетип и символ. М., 1991. C. 203-222.

7. Лиетар Б.А. Будущее денег : новый путь к богатству, полноценному труду и более мудрому миру. М. : КРПА Олимп : АСТ : Астрель, 2007. 493 с.

Boyko Olga A. Orel State University named after I.S. Turgenev (Orel, Russian Federation).

E-mail: boiko_olga@yahoo.com

Tomsk State University Journal of Cultural Studies and Art History, 2016, (3) 23, p. 15-23. DOI: $10.17223 / 22220836 / 23 / 2$

ARCHETYPE OF «SHADOW» IN THE ART OF XX CENTURY

Key words: K.G. Jung, the collective unconscious, the archetype of the «shadow», the art of XX century, Edvard Munch, Kazimir Malevich, Max Ernst. 
In the first part of the study, the author gives the definitions and the characteristic of the phenomenon "archetypes of the collective unconscious" and "archetype of the shadow." Archetypes are defined as stable forms of the collective unconscious, which acquire recognizable semantic and symbolic content in the particular life experience of an individual and society. Archetypes are manifested in various forms of culture through archetypal symbols. The archetype of the "shadow" is characterized as an outward projected personification of the unconscious, as a rule, negative aspects of an individual and collective psyche.

Further, the limits of applicability of the archetypal approach are determined. To do this, the author refers to the analysis of such types of creativity, singled out by K.G. Jung, as a "psychological" and "visionary." The first type offers the audience the material that can be easily interpreted in terms of the life experience of the author and his environment. In contrast, the "visionary type" of creativity has nothing to do with what is familiar and intuitive to the consciousness. In this case, one cannot say that it is really the author who creates the work. Rather, he is a mere translator, passing some contents of the collective unconscious to the audience. Revealing these features, the author shows that the archetypal approach is only applicable to the analysis of "visionary" type works.

In the main part of the article the author chooses as the subject of research such famous paintings masterpieces of the XX century as "The Scream" by E. Munch, "Black Square" by K. Malevich and " The Virgin Spanking the Christ Child before Three Witnesses " by M. Ernst, and offers them for the archetypal study. These works, as the author shows, are characterized by signs of "visionary" type creations and carry the vivid symbols that embody the archetype of the "shadow". The analysis of these works reveals the traits that, being the peculiarities of modern art, are also the reflection of the collective psyche of people of their time. At first sight they demonstrate the desire to show and accept something negative, repulsive, violent and frightening. The author shows how through such works the archetype of the "shadow", long repressed by Western civilization, breaks out to the social surface. Such a breakthrough, according to the author, performs a triple function: firstly, it is a figurative reflection (self-diagnosis) of the destructive tendencies of the era; secondly, through it the era brings its state to the public perception; thirdly, it reflects an attempt of the psychological imbalance compensation of the universal human psychology and culture of the XX century.

\section{References}

1. Jung, C.G. (2009) Eon. Translated from German by M. Sobutsky. Moscow: AST.

2. Jung, C.G., Franz, M.-L., Henderson, J.L., Jacobi, I. \& Jaffe, A. (1997) Chelovek i ego simvoly [Man and His Symbols]. Translated by I. Sirenko, S. Sirenko, N. Sirenko. Moscow: Serebryanye niti.

3. Jung, C.G. (1992) Sobranie sochineniy v 19 t. [Collected Works in 19 vols]. Vol. 15. Moscow: Renessans.

4. Malevich, K. (2004) Sobranie sochineniy: v 5 t. [Collected Works: In 5 vols]. Vol. 5. Moscow: Gileya.

5. Maikapar, A. (2011) Malevich. Moscow: Komsomolskaya pravda.

6. Jung, C.G. (1991) Arkhetip i simvol [The archetype and symbol]. Translated from German. Moscow. pp. 203-222.

7. Lietar, B.A. (2007) Budushchee deneg: novyy put' $k$ bogatstvu, polnotsennomu trudu i bolee mиdroти miru [The Future of Money: a new way to wealth, full employment and wiser world]. Translated from French by O. Goryaynov, E. Ermilova. Moscow: KRPA Olimp: AST: Astrel'. 